\title{
Cloning, Sequencing and In Silico Characterization of OmpF Protein of Salmonella typhimurium for its Immune-Potential
}

\author{
Nimisha Soman $^{1}$, Prejit ${ }^{1,2^{*}}$, P.T. Pratheesh ${ }^{1}$, S.H. Mahesh ${ }^{1}$ and V.K. Vinod ${ }^{1,2}$ \\ ${ }^{1}$ Department of Veterinary Public Health, CV\&AS, Kerala Veterinary and Animal Sciences \\ University, Pookode, Wayanad, Kerala - 673576, India \\ ${ }^{2}$ Centre for One Health Education, Advocacy, Research and Training, Kerala Veterinary and \\ Animal Sciences University, Pookode, Wayanad, Kerala - 673576, India \\ *Corresponding author
}

\section{A B S T R A C T}

Salmonella is a major foodborne bacterial pathogen responsible for millions of cases of infection and thousands of death in humans across the globe annually. Poultry and poultry products are considered to be the major source of Salmonella infection in humans. The

Keywords

Salmonella typhimurium, OmpF, In silico analysis, Vaccine

Article Info

Accepted: 16 April 2018 Available Online: 10 May 2018 economic loss caused by salmonellosis is very huge in case of poultry industry. Vaccination of the poultry is found to efficiently reduce the zoonotic risks associated with Salmonella infection. Virulence nature of outer membrane proteins of Gram-negative bacteria Salmonella is found to efficiently generate immunity in host system. Hence, several efforts have been made to develop an outer membrane protein based vaccine and were found to be successful. So, in the present study outer membrane protein F (OmpF) of Salmonella typhimurium was cloned, sequenced and in silico analysis was carried out to study its structural and immunological characteristics. Antigenic indexing, Epitope mapping and MHC mapping were performed using various prediction servers and online tools. Presence of eight major B cell epitopes indicated ability of OmpF to elicit humoral immunity. VaxiJen score of 0.85 further confirmed the antigenic nature of the epitope. Tcell epitope mapping identified several epitopes with high MHC binding affinity representing ability to provoke cell mediated immunity. The results from the study indicated that OmpF protein of Salmonella typhimurium is a strong candidate for developing recombinant vaccine against salmonellosis in poultry.

\section{Introduction}

Salmonellosis is a most commonly reported foodborne zoonoses in humans (Schlundt, 2004) capable of causing prolonged disease, possible treatment failure and increased severity of disease, mortality and societal costs. The major bacterial etiological agent of salmonellosis includes various pathogenic serovars of Salmonella enterica. Although more than 2500 serovars of Salmonella enterica have been identified, among these $S$. typhimurium was found to be second most common zoonotically important serovar isolated from humans globally (Hendriksen $e t$ al., 2011; CDC, 2013). Many countries are facing this growing public health problem because of its antimicrobial resistance (Davies 
and Davies, 2010; Mir et al., 2015) and easy transmission of Salmonella bacteria through food and water. This organisms seems to be associated with gut of poultry, hence consumption of contaminated poultry meat, egg and its products consumption and contact with infected birds are the major transmission route to humans (Adak et al., 2005).

In developing countries like India, poultry rearing is becoming a profitable sector in agrarian economy. Reports of Salmonella incidence from poultry stock of India indicate the possibility of transferring Salmonella from poultry to human populations where it can cause serious health issues (Kaushik et al., 2014; Sudhanthirakodi et al., 2016). Many strategic control programmes have been investigated to reduce the Salmonella burden from poultry flock. Vaccination along with other control measures is currently being used in poultry industry to reduce the zoonotic risk (Desin et al., 2013). In last few years, vaccine control strategic programmes were in search of a suitable strong immunogenic vaccine candidate, this lead to an extensive study on outer membrane proteins of Salmonella (Hamid and Jain, 2008; Ghosh et al., 2011). Outer membrane proteins are good surface immunogens (Nandakumar et al., 1993), and are used in several studies to investigate the capability as a vaccine candidate in poultry (Meenakshi et al., 1999; Khan et al., 2003; Okamura et al., 2012; Prejit et al., 2013). Studies have also targeted in developments of diagnostic antigen with OMPs (Manoj et al., 2015). OmpC, OmpF, OmpD are the major outer membrane proteins of Salmonella (Singh et al., 2017). However, only limited studies were conducted on OmpF protein of Salmonella Typhimurium. Considering these factors, the present work was undertaken for detailed analysis of omp $\mathrm{F}$ gene, using various online immunological softwares and databases for gene analysis, to interpret information about the proteome to identify and characterize its antigenic properties.

\section{Materials and Methods}

\section{Bacterial strain}

Reference strain Salmonella typhimurium E2375 used in this study was procured from National Salmonella Center, Indian Veterinary Research Institute (IVRI), Izatnagar. Purity and identification of the culture was determined by primary and secondary biochemical test specific to Salmonella. Molecular confirmation was done with Salmonella typhimurium specific primers targeting the stm gene (Liu et al., 2012). Culture was stored and maintained in Hektoen enteric agar at Department of Veterinary Public Health, College of Veterinary and Animal Sciences Pookode, Wayanad, India for further use. One Shot TOP 10 Chemically Competent E. coli cells (Invitrogen, USA) were used as host cell in the cloning reaction.

\section{Cloning of ompF gene}

Genomic DNA of Salmonella Typhimurium was isolated by using mini prep DNA isolation kit, Invitrogen (USA), from $2 \mathrm{ml}$ of overnight grown cultures in LB broth. Concentration and purity of the isolated DNA was checked and stored at $-20^{\circ} \mathrm{C}$ until use. Sequence information of Salmonella typhimurium available on NCBI used for designing of $o m p F$ primers with the help of gene tool software (For- 5'-ATG ATG AAG CGC AAA ATC CTG GC-3' and Rev- 5' TCA GAA CTG GTA AGT AAT ACC GAC AG3 '), and synthesized at IDT, USA.

Amplification of ompF gene was carried out with $25 \mu \mathrm{l}$ of PCR reaction mixture containing 50ng template DNA, $200 \mu \mathrm{M}$ dNTPs, $0.2 \mu \mathrm{M}$ each primers, $1 \mathrm{X}$ Taq buffer, and $0.1 \mathrm{U}$ of high fidelity Taq polymerase Invitrogen (USA) under following cycling condition. Denaturation at $95 \mathrm{C}$ for $5 \mathrm{~min}$ followed by 34 cycles of denaturation $\left(94^{\circ} \mathrm{C}\right.$ for $\left.40 \mathrm{sec}\right)$, 
annealing $\left(56^{\circ} \mathrm{C}\right.$ for $\left.40 \mathrm{sec}\right)$ and extension $\left(72^{\circ} \mathrm{C}\right.$ for $\left.1 \mathrm{~min}\right)$. Final extension was carried out at $72^{\circ} \mathrm{C}$ for $5 \mathrm{~min}$. Amplified products were analyzed and then eluted from the gel using GeneJET Gel Extraction kit (Thermo Scientific, USA).

Eluted $o m p F$ PCR amplicon was ligated in to pCR 2.1 vector (Invitrogen, USA) and it was transformed to One Shot TOP 10 Chemically Competent E. coli cells by heat shock method. Randomly picked white colonies were screened for insert of desired size by colony PCR. Positive clones were grown in ampicillin containing media and plasmid DNA was isolated from the cloned cells by using Pure Link Quick Plasmid Mini Prep Kit (Thermo Scientific, USA). Plasmid was sequenced at DNA sequencing facility Agrigenome, Kochi. Deduced sequences were submitted to NCBI.

\section{Sequence Similarity and Antigenic characterization of $\mathrm{ompF}$}

Sequencing result of $o m p F$ gene was analyzed for homology using Basic local alignment search tool (Altschul et al., 1997). Multiple sequence alignment was performed by using CLUSTAL-W (Thompson et al., 1994).

In silico translation and analysis of primary structure of outer membrane protein were performed using online bioinformatics tool (ExPASy translate tool). Based on primary structure, physiochemical properties of OmpF protein was also deduced using ExPASy ProtParam (Gasteiger et al., 2005). The B cell epitopes of OmpF protein was identified and characterized using BepiPred prediction tool of IEDB analysis (Potocnakova et al., 2016). The sequence was loaded into the tool window and searched for most potential linear epitopes. Antigenic peptides presented by MHC class I and II molecules was recognized by IEDB analysis of $\mathrm{T}$ cell epitope prediction tool.
The secondary structure of $\mathrm{OmpF}$ protein was predicted using SOPMA (Self- Optimized Prediction Method with Alignment) tool (Combet et al., 2000). This tool evaluates the percentage of alpha helices, extended strand, beta turn and random coils. Protein Homology/analogy Recognition Engine V 2.0 (Phyre2) web portal for protein modeling was used to predict the 3D structure (Kelly et al., 2015). SWISS-MODEL protein structure homology-modelling server was used to find structural homology of the protein (Schwede et al., 2003).

\section{Results and Discussion}

Purity of the procured Salmonella typhimurium culture was confirmed using biochemical characterization and PCR analysis using Salmonella typhimurium specific gene primers. The culture was found to be MR+, VP-, Urease-. In PCR analysis 984 bp characteristic amplicon of stm gene was obtained. These results confirmed the identity of the strain.

\section{PCR amplification of omp F gene}

PCR Amplification of $o m p F$ gene was carried out using genomic DNA isolated from $S$. typhimurium, which resulted in a PCR amplicon of size 1092 bp (Fig. 1). The amplified product was purified using gel extraction kit, and cloned in to pCR 2.1vector using TA cloning kit and was transformed to One Shot TOP 10 Chemically Competent $E$. coli cells.

Screening of the transformed colonies on selective agar plates with ampicillin was done by colony PCR (Fig. 2). Plasmid with ompF gene insert was isolated using Pure Link Quick Plasmid MiniPrep Kit (Thermo Scientific, USA) and, sequenced at Agrigenome, Kochi Sequenced data with complete cds of ompF gene was submitted in 
NCBI Gene Bank (Accession number MF593888).

Sequence analysis of $S$. typhimurium ompF gene

The complete omp $\mathrm{F}$ gene sequence of Salmonella typhimurium has shown $100 \%$ identity to outer membrane sequences of many serovars of Salmonella enterica like Typhimurium, Heidelberg, Saintpaul etc. by NCBI BLAST search.

Bioinformatics analysis using ExPASy ProtParam analysis revealed that 363 amino acid containing OmpF protein is having $42.412 \mathrm{KDa}$ size, of these 51 amino acids were strongly basic $(+\mathrm{Ve})(\mathrm{K}+\mathrm{R})$, and 31 were strongly acidic $(-\mathrm{Ve})(\mathrm{D}+\mathrm{E})$ in nature with a theoretical $\mathrm{pI}$ value of 4.51 . Instability index, aliphatic index and Grand average of hydropathicity (GRAVY) was found to be 13.22, 61.46, -0.607, respectively. Proteins with instability index less than 40 indicates that the stability of protein in test tube. Here the OmpF protein is having an instability index of 13.22, showing its stable nature.

It has been previously reported that, $\mathrm{OmpF}$ protein is resistant to high temperature and denaturing agents and preferably expressing at low osmolar conditions (Verma et al., 2009). Aliphatic index of a protein is considered as positive factor for increasing the thermo stability of protein and GRAVY is indicative of hydrophobicity or hydrophilicity of protein. Both the parameters proved that this protein is thermo stable (61.46) and hydrophilic (-0.607) in nature. The estimated half-life of the protein is $30 \mathrm{hrs}$ in mammalian reticulocytes (in vitro), $>20$ hours in yeast (in vivo) and $>10 \mathrm{hrs}$ in E. coli (in vivo).

Pfam analysis revealed that $\mathrm{OmpF}$ protein of $S$. typhimurium belongs to Gram negative porin family. Swiss model analysis showed, 92.8 per cent structural similarity with $\mathrm{OmpF}$ of $S$. typhi. Prosite analysis identified five motifs in OmpF protein of $S$. typhimurium. Casein kinase II phosphorylation site at five locations (47-50, 83-86, 127-130, 258-261, 263-266), single tyrosine kinase phosphorylation site (52-58), N-myristoylation site at nine locations (104-109, 141-146, 154159, 166-171, 172-175, 194-199, 207-212, 288-293, 305-310), three protein kinase phosphorylation sites (150-152, 158-160, 215217) and $\mathrm{N}$ - glycosylation sites at three locations (184-187, 156-259, 272-275). Antigenic characterization of translated protein sequence was done by VaxiJen v2.0 antigen prediction server (Doytchinova and Flower, 2007) and $\mathrm{OmpF}$ protein was found to be antigenic in nature with an overall antigen prediction score of 0.85 . OmpF protein is found to be more antigenic on comparison with OmpC of S. typhimurium (score 0.73).

\section{Protein structural and functional analysis}

ExPASy translate tool translated the nucleotide sequences of $о \mathrm{mp} \mathrm{F}$ to deduce amino acid sequences. On comparison with deduced amino acid sequence of OmpF protein of $S$. typhimurium with other protein sequences available in Gene bank revealed that $100 \%$ homology with phosphorin (PhoE) protein of Salmonella enterica.

Secondary structure analysis using SOPMA tool, it was observed that in OmpF, four types of structures were present, of these $19.01 \%$ were alpha helix, $28.37 \%$ extended strands, $6.06 \%$ beta turns and $46.56 \%$ random coils (Fig. 3). On 3D structure using Phyre2 web portal for protein modeling, prediction and analysis software, output data had a confidence in the model: 333 residues (92\%) modelled at $>90 \%$ accuracy (Fig. 4). 
Table.1 Major B-cell epitopes

\begin{tabular}{|c|c|c|c|c|}
\hline No. & Start & End & Peptide & $\begin{array}{l}\text { Peptide } \\
\text { length }\end{array}$ \\
\hline 1 & 19 & 35 & TANAAEIYNKDGNKLDL & 17 \\
\hline 2 & 38 & 38 & $\mathrm{~K}$ & 1 \\
\hline 3 & 40 & 40 & $\mathrm{~V}$ & 1 \\
\hline 4 & 44 & 95 & $\begin{array}{c}\text { WTTTGDSKNADQTYAQIGFKGETQINTDLTGFGQWEYRTKA } \\
\text { DRAEGEQQNS }\end{array}$ & 52 \\
\hline 5 & 108 & 108 & A & 1 \\
\hline 6 & 110 & 110 & VGSIDYGRN & 9 \\
\hline 7 & 120 & 120 & G & 1 \\
\hline 8 & 126 & 152 & ESYTDMAPYFSGETWGGAYTDNYMTSR & 27 \\
\hline 9 & 154 & 154 & $\mathrm{G}$ & 1 \\
\hline 10 & 176 & 198 & QYQGKNQDNHSINSQNGDGVGYT & 23 \\
\hline 11 & 205 & 243 & GFGVTAAYSNSKRTNDQQDRDGNGDRAESWAVGAKYDAN & 39 \\
\hline 12 & 252 & 254 & AET & 3 \\
\hline 13 & 257 & 257 & M & 1 \\
\hline 14 & 262 & 276 & NTVTDTVEMANKTQN & 15 \\
\hline 15 & 294 & 313 & SYVQSKGKQLNGAGGSADLA & 20 \\
\hline 16 & 317 & 318 & QA & 2 \\
\hline 17 & 321 & 323 & TYY & 3 \\
\hline 18 & 341 & 358 & ENDYSSSYVGTDDQAAVG & 18 \\
\hline
\end{tabular}

Table.2 Prediction of T-cell epitopes of OMP of S. typhimurium

\begin{tabular}{|c|c|c|l|c|c|}
\hline Allele & Start & End & \multicolumn{1}{|c|}{ Peptide } & $\begin{array}{c}\text { Percentile } \\
\text { rank }\end{array}$ & $\begin{array}{c}\text { IC50 } \\
\text { value }\end{array}$ \\
\hline H2-1Ab & 140 & 154 & AYEFDGFGVTAAYSN & 2.86 & 530 \\
\hline & 141 & 155 & YEFDGFGVTAAYSNS & 2.9 & 531 \\
\hline & 139 & 153 & MAYEFDGFGVTAAYS & 3.35 & 623 \\
\hline & 138 & 152 & TMAYEFDGFGVTAAY & 3.4 & 630 \\
\hline & 137 & 151 & YTMAYEFDGFGVTAA & 3.49 & 637 \\
\hline & 142 & 156 & EFDGFGVTAAYSNSK & 4.33 & 801 \\
\hline & 143 & 157 & FDGFGVTAAYSNSKR & 4.38 & 791 \\
\hline & 251 & 265 & DLAKYIQAGATYYFN & 6.44 & 784 \\
\hline & 250 & 264 & ADLAKYIQAGATYYF & 6.46 & 778 \\
\hline & 249 & 263 & SADLAKYIQAGATYY & 6.67 & 775 \\
\hline H2-1Ad & 250 & 264 & ADLAKYIQAGATYYF & 8.66 & 4770 \\
\hline & 180 & 194 & YDANNVYLAAVYAET & 9.51 & 1575 \\
\hline & 247 & 261 & GGSADLAKYIQAGAT & 9.58 & 4292 \\
\hline
\end{tabular}


Fig.1 PCR amplification of ompF gene of Salmonella typhimurium; Lane M: 1kb ladder, Lane 12: PCR amplicons of ompF gene (1092bp)

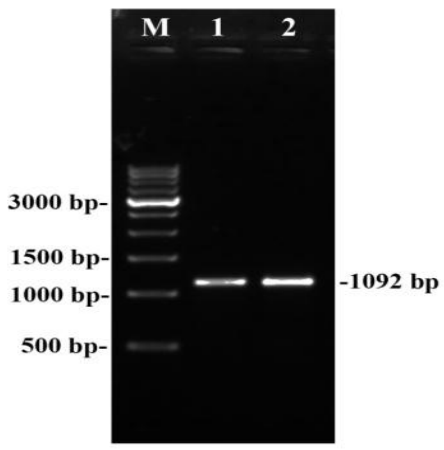

Fig.2 Colony PCR confirming ompF gene in pCR 2. 1vector; Lane M: 1kb ladder Lane 1-5: Positive transformed colonies, Lane 6: Positive control

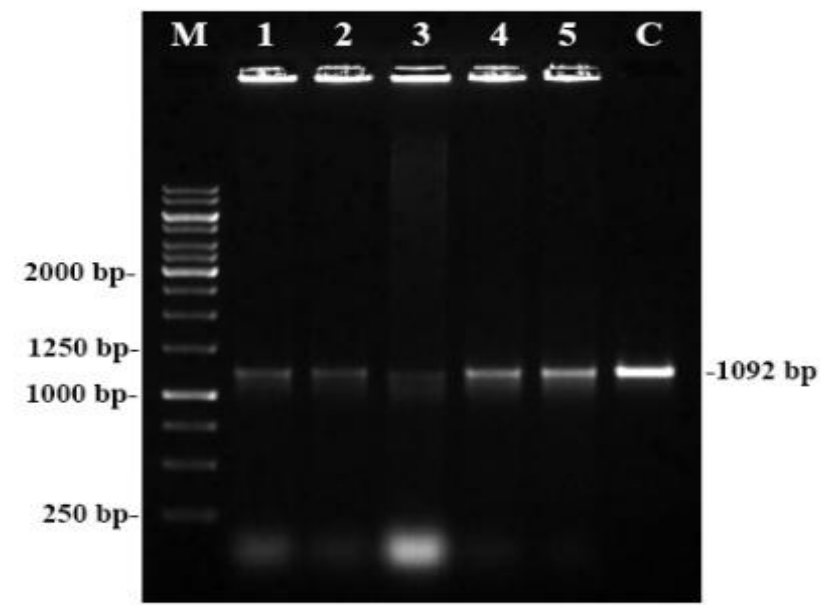

Fig.3 Secondary structure of OmpF of Salmonella typhimurium, with 4 types of secondary structures; Alpha helix (19.01\%), Extended strands (28.37\%), Beta turns (6.06\%) and Random coils $(46.56 \%)$

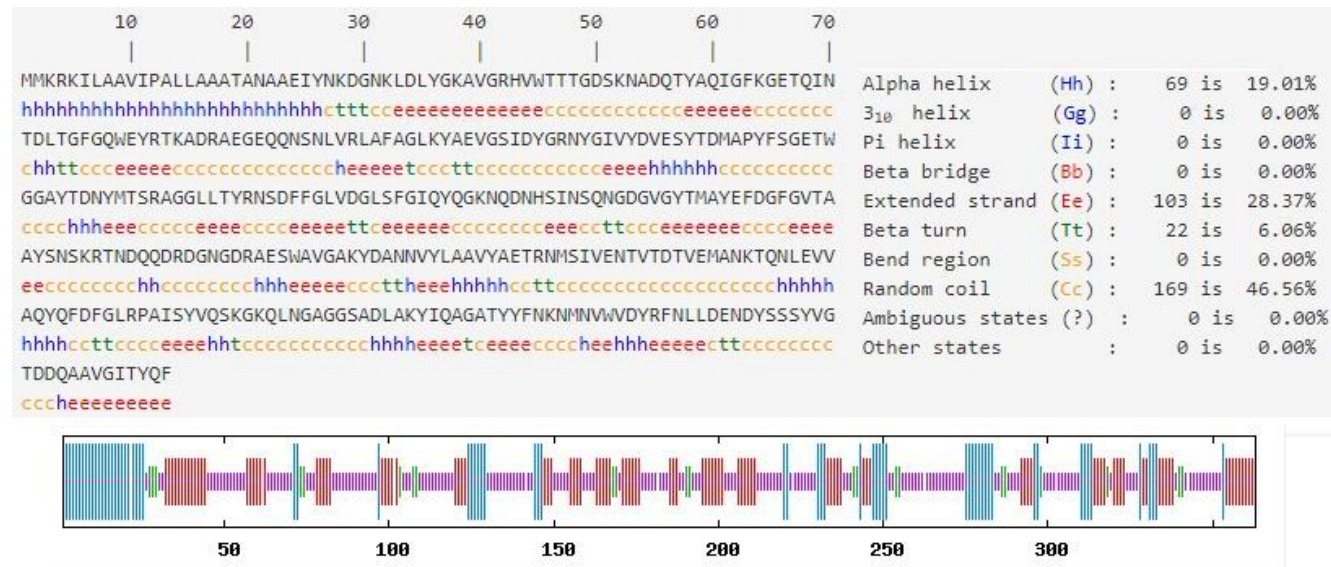


Fig.4 Predicted tertiary structure of OmpF protein of Salmonella typhimurium in three different angles generated using Phyre2 protein modeling tool

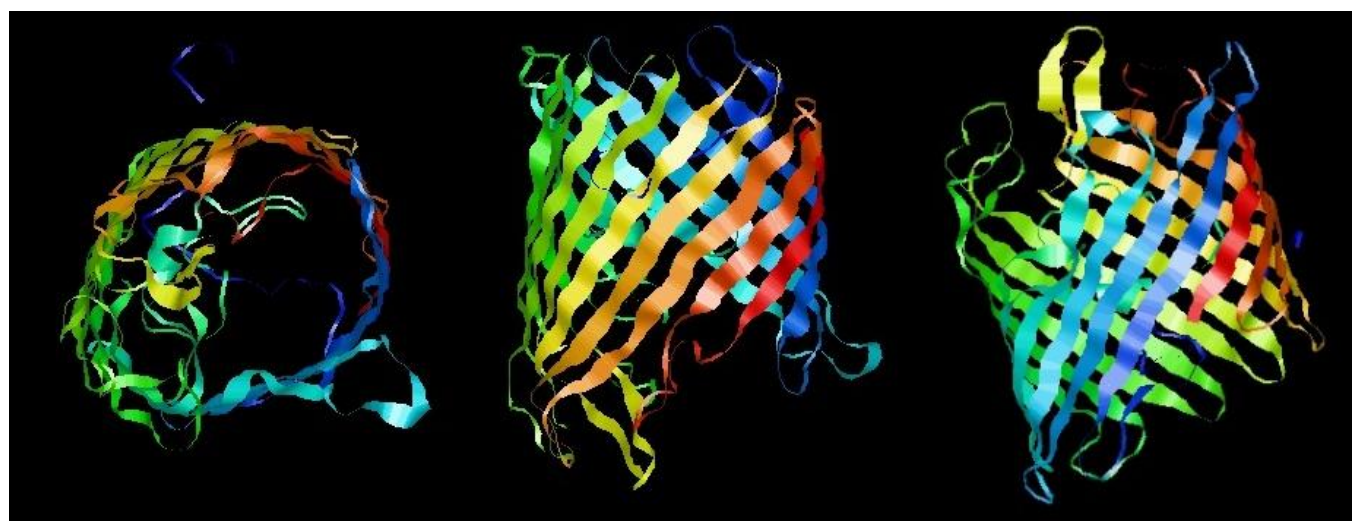

Fig.5 SWISS-MODEL analysis showing OmpF of Salmonella typhimurium having 99.4\% sequence similarity with $\mathrm{OmpF}$ of $S$. typhi and has a similar stable homo-trimer 3D structure
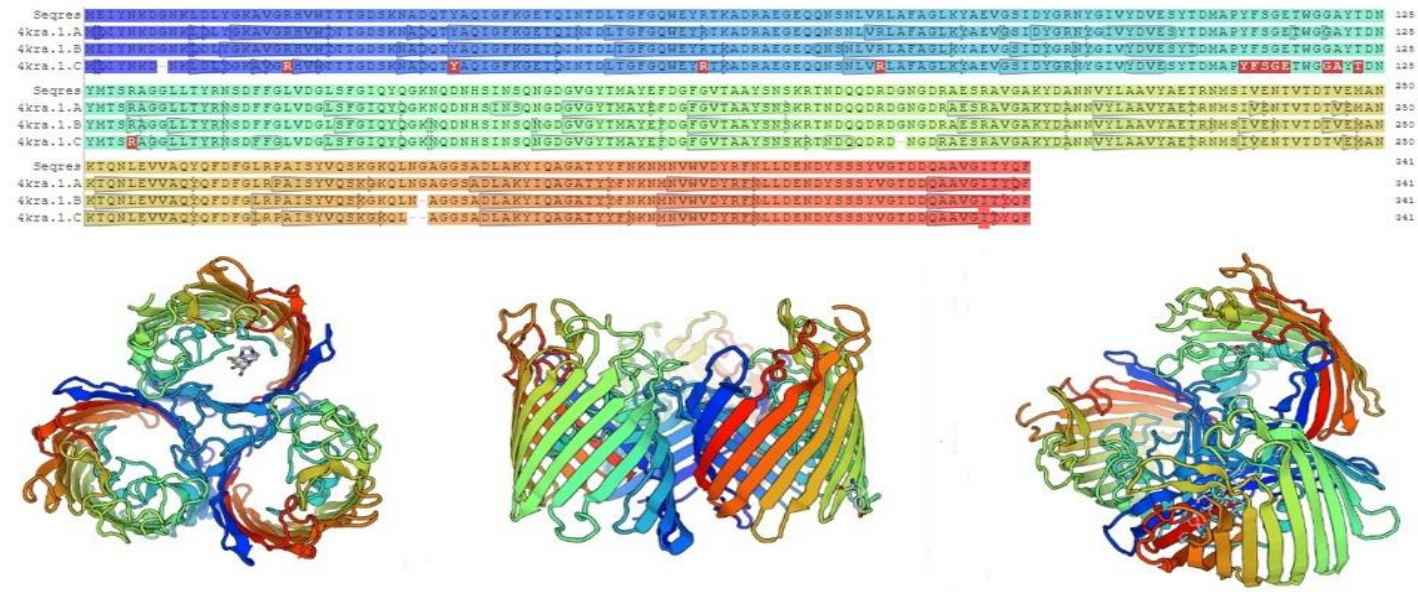

Fig.6 B-cell epitope prediction through IEDB online epitope prediction tool

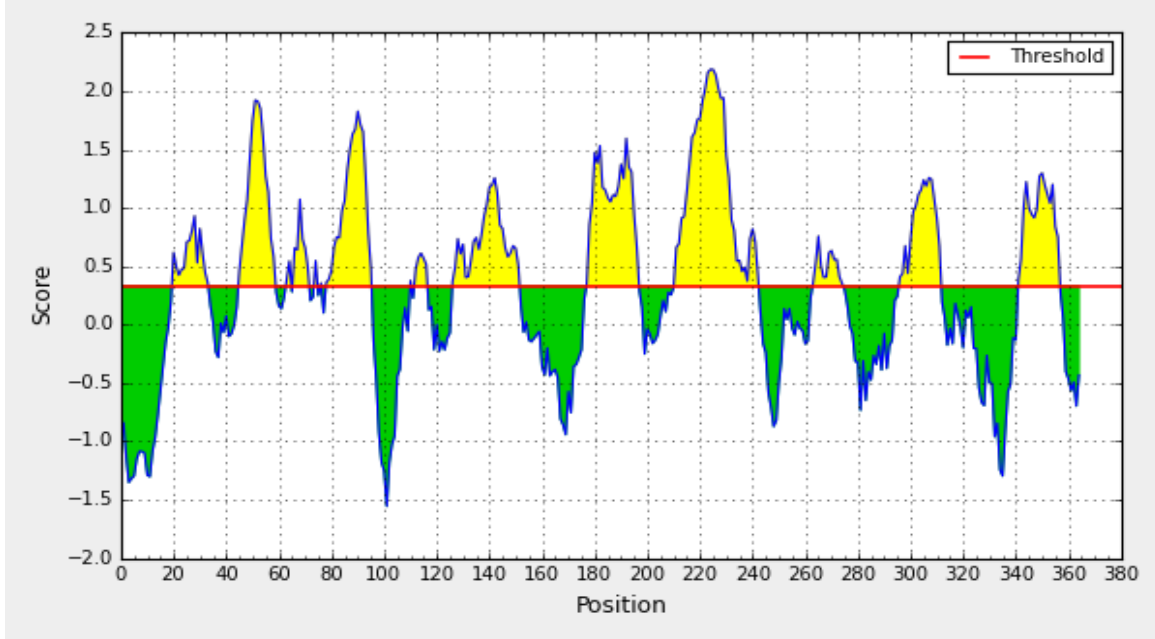


Fig.7 MHC I epitopes identified through IEDB epitope prediction tool

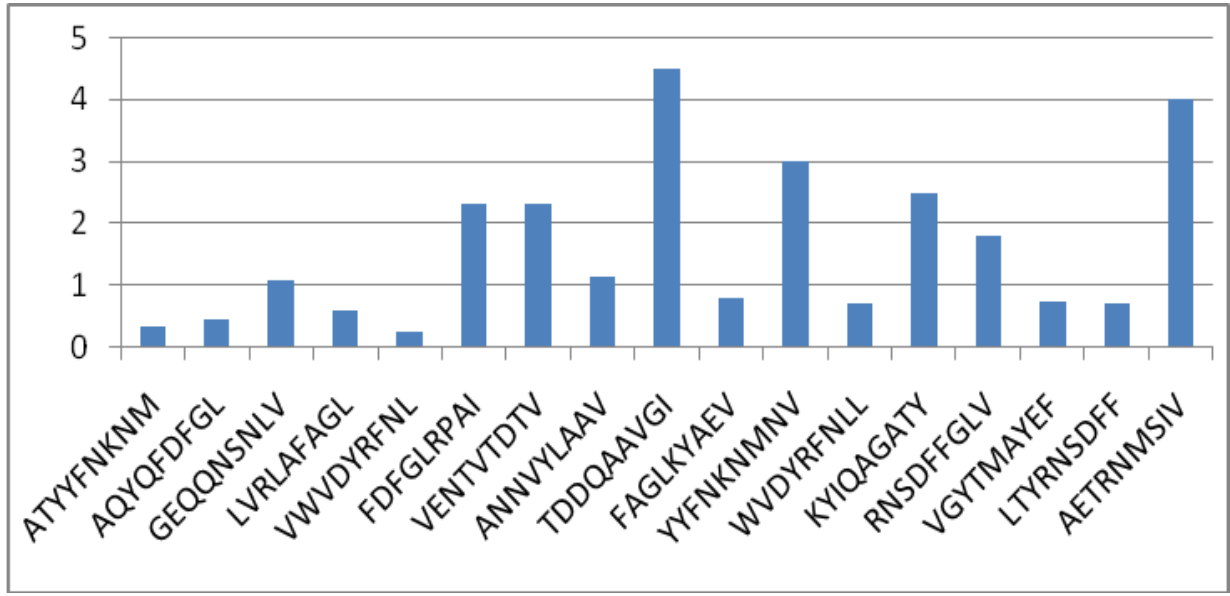

SWISS-MODEL analysis the S. typhimurium OmpF protein with known protein structures homology analysis showed $99.4 \%$ similarity to Salmonella typhi $\mathrm{OmpF}$, which indicate that the protein has a similar stable homo-trimer structure. The structure homology and 3D homo-trimer structure of $\mathrm{OmpF}$ protein is shown in Figure 5.

\section{B-Cell epitope prediction}

Major B cell epitopes of OmpF protein were evaluated for potential linear epitope using Bepipred prediction tool (Fig. 6). A total of 18 $\mathrm{B}$ cell epitopes were predicted by IEDB epitope prediction tool (Table 1). On analyzing the epitope prediction scores, 8 of the epitopes were found to be highly immunogenic in nature. An epitope having 10 or more amino acid are generally considered to be a good B cell epitope to elicit humoral immune response, in case Omp $\mathrm{F}$ protein we found very long epitopes making it a high potential vaccine candidate. In a similar study conducted in OmpC by Jha et al., (2012) there were only $13 \mathrm{~B}$ cell epitopes, and the epitope scores were less in comparison to OmpF in this study.

\section{T-cell epitope prediction}

On MHC class I analysis using IEDB resource based on IC-50 value, 17 MHC-I significant epitopes were identified of these 4 were found to be high affinity epitopes (IC50 value $<50$ $\mathrm{nM})$ and 13 epitopes with intermediate affinity (IC50 value <500 nM) (Fig. 7).

In case of MHC class II there are three different types $\mathrm{H} 2-1 \mathrm{Ab}, \mathrm{H} 2-\mathrm{Ad}$ and $\mathrm{H} 2-\mathrm{Ed}$ alleles in mice. A high affinity MHC binding epitope should have a percentile rank $\leq 10$ and IC50 value at $\leq 1000 \mathrm{nM}$. IEDB also recommended that peptide with low percentile rank have good binding capacity. In case of $\mathrm{H} 2-1 \mathrm{Ab}, 10$ high affinity binding sites were found and $\mathrm{H} 2-1 \mathrm{Ad}$ has only three (Table 2). The interaction between MHC molecules in antigen presenting cells and predicted epitope binding site may have the ability to elicit $\mathrm{T}$ cell mediated immunity (Doytchinova and Flower, 2007; Schuler et al., 2007). Reports of some studies stated that epitope having ability to trigger $\mathrm{T}$ cell and B-cell mediated immunity could be beneficial to develop peptide based vaccine (Barh et al., 2009; Barh et al., 2010). Therefore presence of these epitopes in $\mathrm{OmpF}$ protein can make use of it as an epitope based sub-unit vaccine for broad range of Salmonella serovars. The presence of phenylalanine as the last residue (hydrophobic residue) at the $\mathrm{C}$ terminus is highly conserved among outer membrane proteins. Phenylalanine at $\mathrm{C}$ terminus provide stability and proper assembly of protein into the outer membrane (Ruffolo $e t$ al., 1996) 
Surface proteins of Salmonella have been considered as a potential vaccine candidate. Some of the outer membrane protein had been studied and described its immunogenic potential (Jha et al., 2012; Saxena et al., 2012; Jha et al., 2015).To date, there are only limited studies were conducted on OmpF protein of Salmonella typhimurium. The functional unit of $\mathrm{OmpF}$ porin is a homo-trimer and is formed by 16stranded beta-barrel with three beta barrel monomers in its outer membrane (Balasubramaniam et al., 2012). Trimer assembly and beta barrel are essential for epitope presentation.

This trimeric porin will be expressed in usual culture condition (Nikiado, 1994). Compared to E coli, Salmonella specific conformational epitope is more stable in nature (Arockiasamy et al., 2004). The results from in silico analysis indicate that $\mathrm{OmpF}$ is having better properties on comparison with OmpC protein, with high immunogenic potential. Further investigations need to be carried out to understand the complete vaccine potential of $\mathrm{OmpF}$ protein, and this will reveal the full potential of the protein in future.

\section{Acknowledgment}

The authors are grateful to Kerala Veterinary and Animal Sciences University, India for providing financial support and all the necessary infra-structure for successful completion of this research work.

\section{References}

Adak, G.K., Meakins, S.M., Yip, H., Lopman, B.A. and O'Brien, S.J. 2005. Disease risks from foods, England and Wales, 19962000. Emerging infectious diseases, 11(3): 365-372.

Altschul, S.F., Madden, T.L., Schäffer, A.A., Zhang, J., Zhang, Z., Miller, W. and Lipman, D.J., 1997. Gapped BLAST and PSI-BLAST: a new generation of protein database search programs. Nucleic acids research, 25(17): 3389-3402.
Arockiasamy, A., Murthy, G.S., Rukmini, M.R., Baalaji, N.S., Katpally, U.C. and Krishnaswamy, S. 2004. Conformational epitope mapping of OmpC, a major cell surface antigen from Salmonella typhi. Journal of structural biology, 148(1): 2233.

Balasubramaniam, D., Arockiasamy, A., Kumar, P.D., Sharma, A. and Krishnaswamy, S. 2012. Asymmetric pore occupancy in crystal structure of OmpF porin from Salmonella typhi. Journal of structural biology, 178(3): 233-244.

Barh, D. and Misra, A.N. 2009. Epitope Design from Transporter Targets in $N$. gonorrhoeae. Journal of Proteomics \& Bioinformatics, 2: 475-480.

Barh, D., Misra, A.N. and Kumar, A. 2010. In silico identification of dual ability of $\mathrm{N}$. gonorrhoeae ddl for developing drug and vaccine against pathogenic Neisseria and other human pathogens. Journal of Proteomics \& Bioinformatics, 3(3): 8290.

Barh, D., Misra, A.N. and Kumar, A., 2010. In silico identification of dual ability of $N$. gonorrhoeae ddl for developing drug and vaccine against pathogenic Neisseria and other human pathogens. Journal of Proteomics \& Bioinformatics, 3(3): 8290.

CDC [Center for Disease Control and Prevention]. 2013. Foodborne Outbreak Online Database (FOOD), http://wwwn.cdc.gov/foodborneoutbreaks /Default.aspx. [18 Jan 2018]

Combet, C., Blanchet, C., Geourjon, C. and Deleage, G. 2000. NPS@: network protein sequence analysis. Trends in biochemical sciences, 25(3): 147-150.

Davies, J. and Davies, D. 2010. Origins and evolution of antibiotic resistance. Microbiology and molecular biology reviews, 74(3): 417-433.

Desin, T.S., Köster, W. and Potter, A.A. 2013. Salmonella vaccines in poultry: past, present and future. Expert review of vaccines, 12(1): 87-96. 
Doytchinova, I.A. and Flower, D.R., 2007. VaxiJen: a server for prediction of protective antigens, tumour antigens and subunit vaccines. BMC bioinformatics, 8(1): 4.

Gasteiger, E., Hoogland, C., Gattiker, A., Wilkins, M.R., Appel, R.D. and Bairoch, A. 2005. Protein identification and analysis tools on the ExPASy server. In The proteomics protocols handbook, Humana press. pp. 571-607.

Ghosh, S., Chakraborty, K., Nagaraja, T., Basak, S., Koley, H., Dutta, S., Mitra, U. and Das, S. 2011. An adhesion protein of Salmonella enterica serovar Typhi is required for pathogenesis and potential target for vaccine development. Proceedings of the National Academy of Sciences, 108(8): 3348-3353.

Hamid, N. and Jain, S.K. 2008. Characterization of an outer membrane protein of Salmonella enterica serovar Typhimurium that confers protection against typhoid. Clinical and Vaccine Immunology, 15(9): 1461-1471.

Hendriksen, R.S., Vieira, A.R., Karlsmose, S., Lo Fo Wong, D.M., Jensen, A.B., Wegener, H.C. and Aarestrup, F.M. 2011. Global monitoring of Salmonella serovar distribution from the World Health Organization Global Foodborne Infections Network Country Data Bank: results of quality assured laboratories from 2001 to 2007. Foodborne pathogens and disease, 8(8): 887-900.

Jha, R., Kumar, A., Saxena, A., Pandey, M., Kumar, R. and Saxena, M.K. 2015. Heterogeneous expression and functional evaluation of in silico characterized recombinant OmpC of Salmonella typhimurium as a functional poultry vaccine to eradicate zoonotic transmission. African Journal of Biotechnology, 14(41): 2862-2870.

Jha, R., Kumar, A., Saxena, A., Tamuly, S. and Saxena, M.K. 2012. Cloning, Sequencing and In Silico Analysis of Omp C of Salmonella typhimurium. ISRN veterinary science, 2012: 1-7
Kaushik, P., Kumari, S., Bharti, S.K. and Dayal, S. 2014. Isolation and prevalence of Salmonella from chicken meat and cattle milk collected from local markets of Patna, India. Veterinary World, 7(2): 6265.

Kelley, L.A., Mezulis, S., Yates, C.M., Wass, M.N. and Sternberg, M.J. 2015. The Phyre2 web portal for protein modeling, prediction and analysis. Nature protocols, 10(6): 845.

Khan, M.I., Fadl, A.A. and Venkitanarayanan, K.S. 2003. Reducing colonization of Salmonella enteritidis in chicken by targeting outer membrane proteins. Journal of Applied Microbiology, 95(1): 142-145.

Liu, B., Zhou, X., Zhang, L., Liu, W., Dan, X., Shi, C. and Shi, X. 2012. Development of a novel multiplex PCR assay for the identification of Salmonella enterica Typhimurium and Enteritidis. Food Control, 27(1): 87-93.

Manoj, J., Agarwal, R.K., Sailo, B., Wani, M.A. and Singh, M.K. 2015. Evaluation of recombinant outer membrane protein $\mathrm{C}$ based indirect enzyme-linked immunoassay for the detection of Salmonella antibodies in poultry. Veterinary world, 8(8):1006-1010

Meenakshi, M., Bakshi, C.S., Butchaiah, G., Bansal, M.P., Siddiqui, M.Z. and Singh, V.P. 1999. Adjuvanted outer membrane protein vaccine protects poultry against infection with Salmonella enteritidis. Veterinary research communications, 23(2): 81-90.

Mir, I.A., Kashyap, S.K. and Maherchandani, S. 2015. Isolation, serotype diversity and antibiogram of Salmonella enterica isolated from different species of poultry in India. Asian Pacific Journal of Tropical Biomedicine, 5(7): 561-567.

Nandakumar, K.S., Palanivel, V. and Muthukkaruppan, V.R. 1993. Diagnosis of typhoid fever: detection of Salmonella typhi porins- specific antibodies by inhibition ELISA. Clinical \& 
Experimental Immunology, 94(2): 317321.

Nikaido, H. 1994. Porins and specific diffusion channels in bacterial outer membranes. Journal of Biological Chemistry, 269(6): 3905-3908.

Okamura, M., Ueda, M., Noda, Y., Kuno, Y., Kashimoto, T., Takehara, K. and Nakamura, M. 2012. Immunization with outer membrane protein A from Salmonella enterica serovar Enteritidis induces humoral immune response but no protection against homologous challenge in chickens. Poultry science, 91(10): 2444-2449.

Potocnakova, L., Bhide, M. and Pulzova, L.B. 2016. An introduction to B-cell epitope mapping and in silico epitope prediction. Journal of immunology research, 2016.

Prejit., Agarwal, R.K., Porteen, K., Dubal, Z.B., Asha, K., Singh, S. and Biswas, R. 2013. Evaluation of recombinant outer membrane protein based vaccine against Salmonella syphimurium in birds. Biologicals, 41(3): 1-7.

Ruffolo, C.G. and Adler, B. 1996. Cloning, sequencing, expression, and protective capacity of the oma87 gene encoding the Pasteurella multocida 87-kilodalton outer membrane antigen. Infection and immunity, 64(8): 3161-3167.

Saxena, A., Tamuly, S. and Saxena, M.K. 2012. Cloning, sequencing, and in silico characterization of Omp 28 of Salmonella typhi (strain MTCC 733) to develop rDNA vaccine for typhoid fever. Journal of natural science, biology, and medicine, 3(2): 133.

Schlundt, J., Toyofuku, H., Jansen, J. and Herbst, S.A. 2004. Emerging food-borne zoonoses. Revue Scientifique et Technique-Office International des Epizooties, 23(2): 513-534.

Schuler, M.M., Nastke, M. D. and Stevanovikc, S. 2007. SYFPEITHI: Database for Searching And T-cell Epitope Prediction, Methods in Molecular Biology, 409: 7593.

Schwede, T., Kopp, J., Guex, N. and Peitsch, M.C. 2003. SWISS-MODEL: an automated protein homology-modeling server. Nucleic acids research, 31(13): 3381-3385.

Singh, Y., Saxena, A., Kumar, R., Bhatt, P. and Saxena, M.K.2017. Immunogenic Outer membrane Proteins (Omps) of Salmonella: Potential Candidate for subunit vaccine. Virology \& Immunology Journal, 1

Sudhanthirakodi, S. 2016. Non-typhoidal Salmonella isolates from livestock and food samples, in and around Kolkata, India. Journal of Microbiology and Infectious Diseases, 6(3): 113-120.

Thompson, J.D., Higgins, D.G., Gibson, T.J. and Clustal, W. 1994. Improving the sensitivity of progressive multiple sequence weighing, position-specific gap penalties and weight matrix choice. Nucleic Acids Research, 22(22): 46734680.

Verma, S.K., Gautam, V., Balakrishna, K. and Kumar, S. 2009. Overexpression, purification, and immunogenicity of recombinant porin proteins of Salmonella enterica Serovar Typhi (S. typhi). Journal of Microbiology Biotechnology 19(9): 1034-1040.

\section{How to cite this article:}

Nimisha Soman, Prejit, P.T. Pratheesh, S.H. Mahesh and Vinod, V.K. 2018. Cloning, Sequencing and In Silico Characterization of OmpF Protein of Salmonella typhimurium for its ImmunePotential. Int.J.Curr.Microbiol.App.Sci. 7(05): 1991-2001. doi: https://doi.org/10.20546/ijcmas.2018.705.234 